\title{
Diabetic Gastroparesis: Functional/Morphologic Background, Diagnosis, and Treatment Options
}

\author{
Viktor J. Horváth • Ferenc Izbéki • Csaba Lengyel • \\ Péter Kempler • Tamás Várkonyi
}

Published online: 9 July 2014

(C) Springer Science+Business Media New York 2014

\begin{abstract}
The regulation of gastrointestinal motility mainly involves the smooth muscle, neural (extrinsic and intrinsic), and hormonal elements, the glial cells, and the interstitial cells of Cajal. An orchestrated function of all these components is required for the appropriate propulsive movement of the food in the gastrointestinal tract. Gastroparesis, a pathological slowing-down of gastric emptying, is a result of the damage to the tissue elements involved in the regulation of motility. Gastroparesis is one of the well-known complications of longstanding diabetes mellitus. Although it is rarely a lifethreatening complication, it has a deteriorating effect on the quality of life, leads to unpredictable oscillation of the blood glucose level, and increases the time required for the absorption of food and medicines. This review describes the clinical characteristics of diabetic gastroparesis and summarizes the organic and functional motility abnormalities caused by this
\end{abstract}

This article is part of the Topical Collection on Microvascular Complications-Neuropathy

V. J. Horváth $(\bowtie) \cdot$ P. Kempler

1st Department of Medicine, Semmelweis University, Koranyi

Sandor utca 2/a, 1081 Budapest, Hungary

e-mail: horvathjviktor@gmail.com

P. Kempler

e-mail: kempler.peter@med.semmelweis-univ.hu

\section{F. Izbéki}

Department of Internal Medicine, Szent György University Hospital of Fejér County, Seregélyesi út 3, 8000 Székesfehérvár, Hungary

e-mail: fizbeki@gmail.com

C. Lengyel · T. Várkonyi

1st. Department of Medicine, University of Szeged, Koranyi fasor

8-10, 6720 Szeged, Hungary

C. Lengyel

e-mail: lecs@in1st.szote.u-szeged.hu

T. Várkonyi

e-mail: varkonyitamas@gmail.com complication. Finally, the currently available and potential future therapeutic approaches are summarized.

Keywords Diabetes mellitus · Gastroparesis · Interstitial cells of Cajal · Neural elements · Diabetic gastroparesis

\begin{tabular}{|c|c|}
\hline Abbreviations & \\
\hline ADRA1D & Alpha-1-adrenergic receptor gene \\
\hline AGE & Advanced glycation end products \\
\hline CCK & Cholecystokinin \\
\hline CYP2D6 & Cytochrome P450 2D6 \\
\hline FDA & Food and Drug Administration \\
\hline GCSI & Gastroparesis Cardinal Symptom Index \\
\hline GI & Gastrointestinal \\
\hline GIP & Gastric inhibitory peptide \\
\hline GLP-1 & Glucagon-like polypeptide-1 \\
\hline ICC & Interstitial cells of Cajal \\
\hline IGF-1 & Insulin-like growth factor-1 \\
\hline $\mathrm{KCNH} 2$ & $\begin{array}{l}\text { Potassium voltage-gated channel, subfamily } \\
\text { H [eag-related], member } 2\end{array}$ \\
\hline NK-1 receptor & Neurokinin-1 receptor \\
\hline nNOS & Nitric oxide synthase \\
\hline NOD & Non-obese diabetic \\
\hline NO & Nitric oxide \\
\hline OEP & $\begin{array}{l}\text { National Health Insurance Fund } \\
\text { Administration }\end{array}$ \\
\hline PAGI-QOL & $\begin{array}{l}\text { Patient Assessment of Upper Gastrointesti- } \\
\text { nal Disorders Quality of Life }\end{array}$ \\
\hline PEJ & Percutaneous endoscopic jejunostoma \\
\hline $\mathrm{SCF}$ & Stem cell factor \\
\hline VIP & Vasoactive intestinal polypeptide \\
\hline 5HT receptor & 5-hydroxytryptamine receptor \\
\hline${ }^{99 \mathrm{~m}} \mathrm{Tc}$ & Metastable nuclear isotope of technetium 99 \\
\hline
\end{tabular}




\section{Introduction}

The mixing and the propulsive movement of liquid and solid food arriving into the esophagus and the lower parts of the gastrointestinal (GI) tract require the well-coordinated work of five basic tissue elements: smooth muscle, extrinsic and intrinsic neurons, glial cells, hormonal elements, and the interstitial cells of Cajal (ICCs). Damage to any of these elements leading to an imbalance of the neuromuscular unit will deteriorate the propulsive movement of food to some extent. The degrees to which these elements are involved determine the degree and nature of the functional disorder. The stomach, positioned in the upper tract of the GI system, has a unique role in the processing of food, since it accommodates to the volume of the aliments, stores them, grinds them into small pieces, and transmits the food toward the duodenum. Under physiological conditions, the movement of low-calory liquid food, especially water, toward the duodenum depends on its volume and the pressure pump function of the stomach [1]. Low-calory solid food (such as bread) spends 20-30 min in the stomach, while a continuous peristaltic movement starts at the mid-upper corpus of the greater curvature of the stomach, spreads toward the antral region (usually $3-5$ times per minute) [2], and presses the pieces of food to the almost closed pylorus. This way, the stomach comminutes the solid food and makes it accessible to the digestive enzymes. Hyperosmotic, acidic, or nutrient-rich food makes stomach emptying much slower [3].

The over-slow emptying of solid food from the stomach for a nonmechanical reason is defined as gastroparesis [4]. The etiology of the disease is complex, but in approximately $30 \%$ of the cases it is caused by long-term diabetes. Gastroparesis was one of the first complications of diabetes described [5], and some ancient doctors, such as Aretaeus of Cappadocia, thought that diabetes was a disease of the stomach. The etiology of gastroparesis cannot be identified in about a third of the cases [6]. The symptoms in all cases are chronic and recur frequently [7], including epigastric burning sensation, bloating, early satiety, abdominal discomfort, nausea, and vomiting. In approximately $90 \%$ of the cases, the first symptom of diabetic gastroparesis is continuous nausea of fluctuating intensity. Eighty percent of the patients complain of bloating, and about $60 \%$ present early satiety [6]. Gastroparesis develops in only $5 \%-12 \%$ of patients with diabetes [8], although previous studies reported a higher incidence [7]. Diabetic gastroparesis occurs more frequently in women, in obese patients with poor glycemic control, and in patients where other complications of diabetes have already appeared. Nonetheless, an obvious relationship between the higher glycated hemoglobin ( $\mathrm{HbA1c}$ ) level and the development and severity of gastroparesis has not been clearly established [9]. Another typical characteristic of gastroparesis is the fact that the severity and nature of the symptoms do not correlate linearly with the extent of the slowdown; therefore, analysis of the complaints alone is not sufficient for the diagnosis of impaired motility of the stomach [10]. Furthermore, a normal gastric motility rate does not exclude the possibility that the complaints originate from motility disorders, while a slower gastric motility is not always associated with symptoms [11]. It is important to emphasize that the only manifestation of gastroparesis in some patients without GI symptoms is poor glycemic control, whereas in other cases, the completely opposite phenomenon may be experienced: the presence of obvious symptoms are not related to dysglycemia [12]. Due to delayed food absorption, postprandial hypoglycemia might be a characteristic feature of gastroparesis among insulin-treated diabetic patients. Although slower stomach emptying in a case of long-standing diabetes mellitus rarely leads to life-threatening complications and does not increase mortality [13], it increases the risk of an electrolyte imbalance, as well as hypo- or hyperglycemia. Gastroparesis should also be considered as the underlying mechanism among patients thought to have brittle diabetes.

As in various other areas of medicine, the severity of the disease may be characterized by different scoring systems. In clinical practice, the Gastroparesis Cardinal Symptom Index [14] and the Patient Assessment of Upper Gastrointestinal Disorders Quality of Life [15] questionnaire are used. Further investigations are required to test whether these questionnaires are sufficiently valuable to guide the proper therapeutic approach or how well these scores lead to an estimate of the prognosis of the gastric complication.

\section{Motility Disorders in Diabetic Gastropathy}

Approximately $18 \%$ of diabetic patients display some kind of upper GI symptoms [16]. The connection between symptoms and motility disorders related to gastroparesis is rather poor $[17,18]$. An increased rate of stomach emptying is a characteristic finding in patients with a relatively short diabetes history (less than 2 years) and without the signs and symptoms of diabetic neuropathy [19]. Faster than normal stomach emptying can be observed even in long-term type 1 diabetes mellitus [12]. In animal models, insulin therapy in a subtherapeutic dosage normalized increased stomach emptying [20]. The most important consequence of faster gastric emptying in clinical practice is sudden postprandial hyperglycemia shortly following food intake. It is also possible that this increased rate of stomach emptying is a preliminary phase of later slower stomach emptying [21].

Diabetic gastroparesis involves a severe delay of stomach emptying of both solid and liquid food [22]. In a survey, type 2 diabetic patients with delayed emptying were older, had higher body mass index, and exhibited more intensive nausea and early satiety, as compared with type 1 diabetic patients 
with impaired gastric motility [23]. Several functional changes can be found in the background of slower stomach emptying [21-24]. However, acute and chronic hyperglycemia have different effects on stomach motility.

In healthy volunteers, severe artificial hyperglycemia causes slowing-down of the emptying of nutrient-containing liquid and solid food [25]. In type 1 diabetic patients with diabetic autonomic neuropathy, hyperglycemia increases the frequency of rhythmic activity in the stomach, resulting in tachygastria [26]. Obvious deleterious effects of hyperglycemia cannot be confirmed on ICCs (cells generate and propagate electrical activity in the stomach and the GI tract) [27]. Interestingly, in type 1 diabetic patients without autonomic neuropathy, the stomach emptying can be significantly decreased even if the postprandial blood glucose elevation does not exceed the physiological range [28].

Chronic hyperglycemia in diabetes can also be responsible for all of the above-mentioned motility disorders. However, it is important to consider that diabetes is associated not only with elevated blood glucose levels, but additionally with an absolute or relative absence of insulin. The importance of this phenomenon is revealed by in vitro experimental data demonstrating the deteriorating effect of the absolute absence of insulin on stomach ICCs and the smooth muscle cells [27]. In general, slower movement of solid food from the stomach in diabetes is more frequent than slower movement of liquids. The impaired pyloric pressure pump function also has an effect on solid food emptying [29], and the dilatation of the distal stomach also relates to the antral hypomotility [30]. The decreased smooth muscle contraction might be explained by smooth muscle myopathy [27, 29] and/or inappropriate function of the stomach pacemaker activity and leads to disturbances of the coordination of electromechanical coupling [31]. It is probably important that the slow waves of the stomach generated by the ICCs are modified by a number of factors, such as the sympathetic-parasympathetic balance, eating, and medicines. Any disturbance in these factors can worsen the effectivity of the peristalsis [18].

The reasons for the discrepancy between the symptoms and detectable motility disorders are not clear; a possible explanation is the viscero-sensory functional defect related to diabetic autonomic neuropathy. The increased activity or sensitivity of these neuronal systems in the proximal stomach might explain the generation of nausea, vomiting, early satiety, and epigastrial pain experienced in type 1 diabetic patients without substantial motility disorders [32].

\section{Cellular-Level Changes in Diabetic Gastroparesis}

The morphological background of diabetes-related GI complications is still not clear. Various factors can damage different tissues, including hyperglycemia and an absolute or relative lack of insulin. The increase in mitochondrial superoxide activity caused by the increased glucose burden can be an important factor in the development of chronic morphologic complications of diabetes [33]. The increased oxidative stress-related decrease in nitric oxide (NO) concentration, together with the reduced activity of heme oxygenase, is an important feature of the pathogenetic background at the cellular level [34]. Carbon monoxide (produced by heme oxygenase) has a protective effect on the ICCs [35].

Histological changes in long-standing diabetes can also be studied. In a human investigation in antrum samples, mild lymphocytic infiltration in the myenteric plexus was a characteristic finding of diabetic gastroparesis [36]. Significant reductions in the numbers of neuronal elements and the ICCs in the antrum wall were detected [37]. In another investigation, the loss of neuronal elements was proven in diabetic samples from the mucosal layer [38]. In a larger study [39], the most frequent abnormality was damage to or loss of the ICCs and the decrease in the number of NO synthase (NOS)positive neurons. However, the loss of the NOS-positive neurons was more characteristic for idiopathic gastroparesis. Electromicroscopic investigations detected a significant increase in the amount of connective tissue. Overall, the most characteristic histopathological change in diabetic gastroparesis is the loss of or damage to the ICCs. The pathophysiologic steps leading to ICC damage are complex. The ICCs are very sensitive to the lack of insulin, despite the absence of insulin receptors and insulin-like growth factor-1 (IGF-1) receptors on these cells [40]. The explanation of this paradoxical situation was provided by experiments [41] that revealed that the smooth muscle cells of the stomach have insulin and IGF-1 receptors and these cells produce the stem cell factor (SCF) that is essential for the development and maintenance of the network of ICCs. The smooth muscle atrophy that develops in the lack of insulin is responsible for the decreased production of SCF and, hence, for the damage to the ICC network [27, 40]. The exact mechanism of ICC damage is still not clear, and several questions remain to be answered $[42,43]$. The most characteristic histological findings and symptoms of diabetic gastroparesis are listed in Tables 1 and 2 .

Table 1 Histological findings in diabetic gastroparesis in human investigations

Reductions in the numbers of neuronal elements (especially nitric oxide synthase positive neurons)

Damage or loss of interstitial cells of Cajal in the myenteric or intramuscular layer (most characteristic finding)

Increase in the amount of connective tissue

Abnormal immune infiltrate (CD45- and CD68-positive cells)

Smooth muscle atrophy 
Table 2 Symptoms and sign of diabetic gastroparesis

Nausea (in about $90 \%$, the first symptom)

Bloating (80\%)

Early satiety $(60 \%)$

Abdominal discomfort or pain

Vomiting

Epigastric burning sensation

Poor control of blood sugar

Poor appetite and weight loss

\section{Role of Neuropathy in the Pathogenesis of Gastroparesis}

The Contribution of Impaired Autonomic Function to the Development of Delayed Gastric Emptying

The motor, secretory, and sensory functions of the stomach may all be altered when the balance is impaired between the intrinsic enteral and the extrinsic (parasympathetic [vagal] and sympathetic [mesenteric] fibers $\}$ autonomic neuronal systems [24]. The parasympathetic regulation can exert both excitatory and inhibitory effects, while the sympathetic input is generally inhibitory, with the exception of its propulsive influence on the lower esophageal sphincter [44]. In accordance with the previous description, GI autonomic neuropathy is the result of a complex pathophysiological process that involves organic and functional impairments of the neuronal cells and a progressive imbalance of various autonomic regulations. The changes include reduced numbers of ICCs, extrinsic autonomic neurons, and smooth muscle cells with altered inhibitory neurotransmission [29]. In patients with diabetic gastroparesis, a reduction in the intraneuronal levels of NO has also been observed [45]. It is assumed that the leading pathophysiologic abnormality is the impairment of parasympathetic function in autonomic neuropathy. Sham feedinginduced gastric acid production or pancreatic polypeptide response to hypoglycemia is decreased in diabetic patients as well. Since both the gastric secretory function and pancreatic polypeptide secretion are under vagal control, these observations support the role of parasympathetic damage in the development of diabetic gastroparesis [46, 47]. The long-term diabetic exposure is one of the most important risk factors of autonomic neuropathy, as indicated in the EURODIAB IDDM study [48]. The progression of the impaired gastric emptying seems to be slower than the progression of the autonomic neuropathy [49]. Besides the chronic metabolic exposure, acute hyperglycemia can also alter GI vagal functions [50]. Moreover, current hyperglycemia affects parasympathetic cardiac functions even in healthy subjects, pointing to the importance of the physiological condition of all those factors that possibly affect the vagal control in the regulation of gastric emptying [51]. The emptying of the stomach might be slower when the balance between the excitatory and inhibitory regulations of the autonomic system becomes disturbed [52]. Parasympathetic function becomes abnormal earlier during the progression of autonomic neuropathy than does the sympathetic function, leading to weakening of the excitatory parasympathetic innervation of the stomach and a relative strengthening of the inhibitory sympathetic effects [53]. The alteration in the sympathetic function can also have detrimental effect on gastric emptying.

Several important processes are regulated by the sympathetic nervous system, which may also partially affect the gastric motility (visceral reflexes, nausea, vomiting, and abdominal pain). Despite the well-known general consequences of the parasympathetic and sympathetic impairments, it is still not clear how these alterations act directly on the motility of the stomach in diabetic patients. Besides the normal extrinsic autonomic neuronal functions, intact central neuronal regulation is also mandatory for the integrity of gastric emptying. Abnormal visceral hypersensitivity as a result of an altered afferent central function is a newly documented source of various digestive symptoms that are responsible for an impaired quality of life [54]. In line with this, a recent study demonstrated altered central sensory processing in diabetic patients with upper abdominal symptoms [55]. A few clinical observations suggest the role of the central neuronal system in the regulation of certain visceral functions, including gastric motility [56]. The severity of the autonomic neuronal damage in humans is not yet measurable directly; therefore, reproducible and sensitive cardiovascular and sensory tests are applied to estimate the neuronal dysfunctions in patients with abnormal gastric emptying or GI symptoms. In some of these tests, correlations have been found between neuropathy and stomach motility. The overall autonomic neuropathy score calculated from cardiovascular reflex tests correlated positively with the scintigraphic gastric emptying rate of solids in patients with long-standing type 1 diabetic patients [57]. Two heart rate tests of the five cardiovascular tests consistently correlated with the emptying of an isotope-labeled solid meal from the stomach in long-standing type 1 diabetes [52]. These heart rate tests, the heart rate response to deep breathing, and the Valsalva maneuver are regarded as sensitive indicators of the parasympathetic function that become abnormal during the early course of neuropathy. These data support the hypothesis that the insufficiency of the excitatory effect of the vagal nerve on the postprandial phase of the stomach functions leads to delayed emptying in type 1 diabetic patients with long duration. Reduced heart rate variability, a well-known indicator of the autonomic dysfunction, was associated with GI complaints in diabetic patients with sensorimotor neuropathy, suggesting a concomitant role of various manifestations of neuropathy in the pathogenesis of digestive complications [58]. Although several studies have documented correlations between neuropathy tests and gastric emptying, numerous 
other studies did not discern any relationship [59]. This might be explained in terms of the restricted methodology of the measurement of the complex GI neuronal dysfunctions, the heterogeneity of the tests applied in the various studies, and the importance of pathophysiological factors other than neuropathy in the pathogenesis of gastroparesis.

\section{The Role of Nitric Oxide Synthase in the Development of Diabetic Gastroparesis}

The NOS-positive neurons identified in the GI tract have a crucial role in the inhibitory regulation of the motility functions and, hence, in the relaxation of the different sphincters. It has been confirmed in animal models that inhibition of neuronal NOS results in slower stomach emptying. Human investigations have revealed that the endogenous NO inhibits the propulsive movement in the stomach [60]. The clinical observation that diabetic gastroparesis predominantly affects women might be related to the fact that impairment of the nitrergic system is more pronounced in females [61]. It has been revealed in animal models that the number of NOSpositive neurons decreases in diabetes and, in parallel with the loss of these neurons, the regulation of pyloric relaxation, just as the antral tone deteriorates. Early treatment with insulin led to rearrangement of the presence of NOS-positive neurons and their synthetic function [20]. A possible future therapeutic approach may be to transplant stem cells that can differentiate into NOS-positive enteral neurons [62].

\section{The Role of Enteral Hormones in the Development of Diabetic Gastroparesis}

The role of these hormones in the pathomechanism of diabetic gastroparesis is still controversial. The effects of the hormones that stimulate (e.g., serotonin, gastrin, acetyl choline, motilin, and substance $\mathrm{P}$ ) or inhibit (NO, vasoactive intestinal peptide, cholecystokinin, gastric inhibitory polypeptide or glucosedependent insulinotropic peptide, secretin, glucagon-like peptide) gastric emptying can be deteriorated either by the glycation of these hormones or their receptors or through the loss of the function of their target organs. One of the most frequently investigated enteral hormone is GLP-1, since dipeptidyl-peptidase-IV inhibitors and GLP-1 analogues and agonists are increasingly more widely used in clinical practice. The consequences of elevations or reductions of this peptide in diabetes have been analyzed, and an association was proven between the effect of GLP-1 on gastric emptying and the elevation of postprandial glucose levels [63]. Ghrelin has also been a target molecule in recent investigations. Although in a species-specific manner, ghrelin promotes the antro-pyloric coordination and can thereby improve stomach emptying $[64,65]$. Ghrelin receptors are located in the highest concentrations on antral and duodenal neurons, with decreasing amounts toward the distal regions [66]. Accordingly, it can be assumed that ghrelin has effects on vagal nerves [67], and the connection between neuropathy and enteral neurons is also indicated [68]. The multiple aspects of the effects of enteral hormones can be further exemplified by the fact that some of the enteral hormones (GLP-1, peptide YY, and gastrin) promote the survival of the pancreas beta cells, which can have a beneficial influence on GI function [69].

\section{The Role of Enteric Glial Cells on the Development of Motility Disorders in Diabetes Mellitus}

Enteric glial cells (EGCs) outnumber the enteral neurons in a ratio of $2: 1$. In view of the close anatomical and functional connection between enteric neurons and EGCs [70, 71], it can be assumed that damage to these cells plays an important role in the diabetes-related impairment of the enteric nervous system and, hence, in motility disorders. However, this close neuron-glia connection complicates the separate in vivo investigation of these cells. Conditional ablation of the EGCs induces changes in the neurochemical coding of enteric neurons, which may be responsible, in part, for the reduced gastric emptying and intestinal transit [72]. In an in vitro study, viral targeted ablation of EGCs increased the level of neuronal death in the presence of oxidative stress because the neuroprotective effects of the EGCs via their release of glutathione were missing [73]. Oxidative stress also activates mechanisms that result in glia-mediated inflammation that causes secondary neuronal damage [74]. The complex role of EGCs in diabetes-related gastric motility disorders has not yet been clearly identified, but their potential targeted influence may open up new therapeutic approaches.

\section{Diagnosis}

Scintigraphic Gastric Emptying Procedure

The standard method for the diagnosis of diabetic gastroparesis is the scintigraphic evaluation of stomach emptying. Recent developments in ultrasonography make this technique too suitable for the evaluation and diagnosis of impaired gastric emptying. In clinical practice, when GI symptoms appear, patients should undergo routine gastroscopy, during which the possibility of slower stomach emptying may be suspected.

The standardization of the scintigraphic measurement of stomach emptying has raised a number of questions, since numerous factors influence gastric emptying [75]. The rate of gastric emptying is frequently defined by using ${ }^{99 \mathrm{~m}} \mathrm{Tc}$-sulfur 
colloid-containing eggs. During the procedure, the imaging is carried out at minute intervals while the patient is lying in supine position. Medicines that affect the gastric motility have to be avoided for at least $72 \mathrm{~h}$ before the investigation. The blood glucose level must be kept in a narrow range during the procedure (between 4 and $10 \mathrm{mmol} / \mathrm{l} ; 72-180 \mathrm{mg} / \mathrm{dl}$ for $2-$ $4 \mathrm{~h}$ ). The diagnosis of gastroparesis can be established if $60 \%$ or more of the activity of the isotope remains in the stomach $2 \mathrm{~h}$ after the test meal ingestion or if at least $10 \%$ of the initial activity is still detected after $4 \mathrm{~h}$. The diagnostic steps for evaluating diabetic gastropathy are shown in Fig. 1.

\section{Investigation of Gastric Emptying by Ultrasonography}

The evaluation and follow-up of gastric emptying by ultrasonography is a convenient noninvasive method. An experienced physician visualizes the structure of the gastric wall by means of ultrasonography and can gain information about the intragastric dispersion of solid food, the accommodation of the stomach, the number of antral contractions, and the transpyloric flow of chopped food [76]. Ultrasonography provides more details of the stomach motility than does scintigraphy, and its sensitivity and specificity might be comparable to those of the isotopelabeling technique [77]. Through the use of 3-D techniques, the gastric volume changes over time can be evaluated more exactly, and the correlation between the findings of this technique and those of scintigraphy becomes more pronounced [78].

\section{Therapeutical Approaches}

In everyday practice, the available therapeutic approaches focus on the symptoms; no causal therapy is yet available, although stem cell replacement therapy (so far carried out only in animal experiments) raises the hope of long-term causal therapy.

The most important treatment option is still optimal glycemic control. Gastric motility disorders and the different stages of glucose metabolism mutually affect each other from several respects. Better glycemic control can improve the motility disorders, which creates an opportunity for stabilizing the blood glucose fluctuations. Adherence to the recommended diet is a crucial point of the treatment. Patients with diabetic gastroparesis should eat small meals, and eating is recommended 6-8 times a day. Solid food should be comminuted as much as possible. Meat containing large amount of dietary fibres or fatty acids should be avoided. Postprandial glucose level in patients with diabetic gastroparesis can be successfully decreased only if the suggested dietary rules are strictly observed [79].

The use of medication to treat diabetic gastroparesis is rather complicated. Prokinetic drugs seem to be right choices, since they improve gastric motility and promote the emptying of carbohydrates, ensuring better conditions of absorption in the small bowel. On the other hand, there is very little evidence that the improvement of motility achieved with these drugs stabilizes glycemic control [19]. Metoclopramide, a peripheral dopamine-2 receptor antagonist and, in part, an agonist of the peripheral serotoninergic 5-hydroxytryptamimne-4 (5-HT4) and vagal and brainstem 5-HT3 receptors, has combined effects (the increase of gastric contractility and the improvement of the relaxation of the pyloric sphincter and the bulbus, moderate nausea, and vomiting via affecting central dopaminergic receptors) and seemed to be promising medication for the treatment of diabetic gastroparesis [80], but its long-term efficacy has not been proven [81], and it has no obvious positive effect on the symptoms of diabetic gastroparesis and glucose metabolism
Fig. 1 Diagnostic steps for evaluating diabetic gastropathy. If symptoms (especially recurrent vomiting and nausea) are present, gastroscopy must be completed. It can exclude other causes of gastroparesis and can raise the possibility of motility disorder. An experienced physician can diagnose gastroparesis with ultrasonography. On the other hand, for the time being, scintigraphy is the most exact diagnostic step for evaluating gastroparesis. Note that other causes have to be excluded before the diagnosis is established

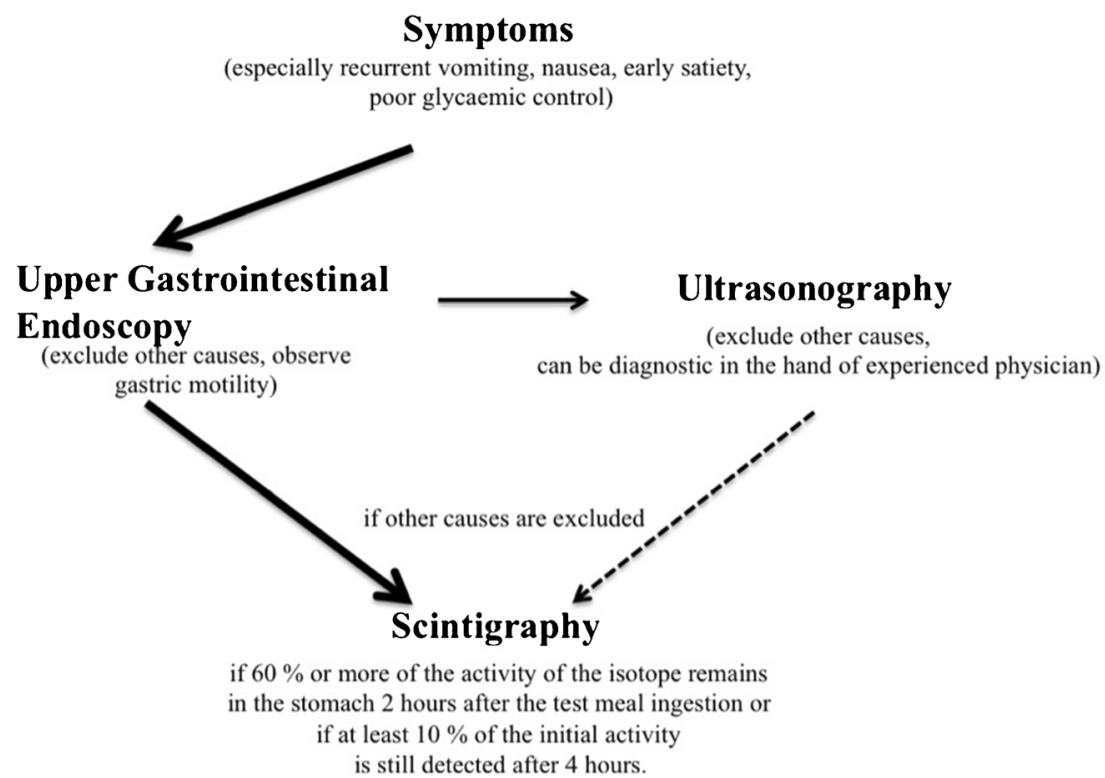


[82]. Since diabetic gastroparesis is a chronic disease, the medicine is usually used for long-term treatment in clinical practice, although its effectivity diminishes with time and side effects become more frequent and pronounced. Some genetic factors have been reported to influence the effectiveness of the drug (polymorphisms in the potassium voltage-gated channel, subfamily $\mathrm{H}$ [eag-related], member 2, and the alpha-1-adrenergic receptor genes); the side effect is predicted by the polymorphism of the CYP2D6 and serotonin 5-HT4 receptor genes [83].

Another prokinetic drug for the treatment of diabetic gastroparesis is domperidone. This drug has a similar effect to that of metoclopramide, but its side effects are not so frequent, because it has no central effect, except for an elevation of the prolactin level. However, sudden cardiac death occurred more frequently among the patients treated with domperidone than among the controls. The explanation was based on the prolongation of the QTc interval [84]. Careful usage of this drug is required from health-care professionals. Domperidone is not currently a legally marketed drug or approved for sale in the U.S.

Erythromycin is an effective motilin receptor agonist [85]. Other macrolides, such as azithromycin, also improve the antroduodenal contractions [46]. Azithromycin does not participate in significant drug-drug interactions and may be of greater clinical importance in the treatment of gastroparesis [86]. The down-regulation of motilin receptors frequently leads to tolerance (tachyphylaxis). Macrolides also have a QTprolonging effect, and some investigations have also shown an increase in sudden death following the application of this drug [87]. Administration of macrolides with the indication of motility enhancement is limited, with the exception of acute exacerbations, when they are administered intravenously.

Alpha-lipoic acid is an effective agent in the pathogenetically oriented treatment of diabetic neuropathy [88], and its beneficial effects on the cardiovascular manifestations of autonomic neuropathy have been proved [89]. These data may support the theory that the autonomic neuronal fibers that are responsible for gastroparesis might respond to alphalipoic acid treatment, but no studies have yet been organized to explore this possible effect. As benfotiamine blocks the four hyperglycemia-induced pathways, it exerts an antioxidative effect, resulting in an improvement in painful neuropathy [90]. This effect might theoretically be utilized in the treatment of GI neuronal dysfunctions, but no clinical observations have been published to confirm this hypothesis yet.

Some promising motility-enhancing drugs have appeared in the experimental phase recently [46], and the modulation of the effect of ghrelin, regulating food intake and gastric emptying in healthy subjects, seems to be also a promising approach $[91,92]$. Further investigations are required to find their place in clinical practice.

Selective substance $\mathrm{P}$ receptor (NK-1 receptor) agonist aprepitant effectively moderates the complaints in diabetic gastroparesis [93]. In most countries, aprepitant is registered only for the treatment of chemotherapy-related nausea. The effectiveness of other antiemetics, such as ondansetron or promethazine, has not yet been proven in the treatment of diabetic gastroparesis [46], and their use is therefore not recommended.

\section{Nonpharmacological Treatment of Diabetic Gastroparesis}

The currently available medicines are not suitable for recovery of the physiological pattern of gastric motility. Moreover, they cannot treat the gastroparesis itself, and they do not have longterm efficacy against the symptoms. Surgical, endoscopic (botulinum toxin injection and percutaneous endoscopic jejunostomy), electric stimulatory possibilities (gastric electrical neurostimulation and gastric electrical pacing), and even acupuncture for the treatment of the disease have been tested, but none of these methods became a part of the routine clinical practice [94-99].

\section{Conclusion}

Gastroparesis is a well-known but difficult-to-treat complication of long-standing diabetes mellitus. Its exact pathomechanism is still not known, although more and more data become available as regard to the complex mechanisms in the background of this complication. Unfortunately, no uniquely effective medical or other treatment is available for influencing the disease, but some promising techniques (such as stem cell replacement or gastric pacing) and new drugs (e.g., ghrelin agonists) raise the possibility that successful treatment options will become available in the near future.

\section{Compliance with Ethics Guidelines}

Conflict of Interest Viktor J. Horváth, Ferenc Izbéki, Csaba Lengyel, Péter Kempler, and Tamás Várkonyi declare that they have no conflict of interest.

Human and Animal Rights and Informed Consent This article does not contain any studies with human or animal subjects performed by any of the authors.

\section{References}

1. Collins PJ et al. Role of the proximal and distal stomach in mixed solid and liquid meal emptying. Gut. 1991;32:615-9.

2. O'Grady $\mathrm{G}$ et al. Origin and propagation of human gastric slow-wave activity defined by high-resolution mapping. Am J Physiol Gastrointest Liver Physiol. 2010;299(3):585-2.

3. Wood JD. Neurogastroenterology and motility. In: Rhoades RA, Bell DR, editors. Principles of medical phisiology. 3rd edn. LWW; 2009. pp. 483-6. 
4. Kashyap P et al. Diabetic gastroparesis: what we have learned and had to unlearn in the past 5 years. Gut. 2010;59:1716-26.

5. Rundles RW. Diabetic neuropathy: general review with report of 125 cases. Medicine. 1945;24:111-60.

6. Soykan I et al. Demography, clinical characteristics, psychological and abuse profiles, treatment, and long-term follow-up of patients with gastroparesis. Dig Dis Sci. 1998;43:2398-404.

7. Feldman $\mathrm{M}$ et al. Disorders of gastrointestinal motility associated with diabetes mellitus. Ann Intern Med. 1983;98:37884.

8. Camilleri M. Clinical practice. Diabetic gastroparesis. N Engl J Med. 2007;356:820-9.

9. Jones KL et al. Predictors of delayed gastric emptying in diabetes. Diabetes Care. 2001;24:1264-9.

10. Barucha AE et al. Relationship between clinical features and gastric emptying disturbances in diabetes mellitus. Clin Endocrinol (Oxf). 2009;70(3):415-20.

11. Ebert EC. Gastrointestinal complications of diabetes mellitus. Dis Mon. 2005;51(12):620-63.

12. Nowak TV et al. Highly variable gastric emptying in patients with insulin dependent diabetes mellitus. Gut. 1995;37:23-9.

13. Kong MF et al. Natural history of diabetic gastroparesis. Diabetes Care. 1999;22:503-7.

14. Revicki DA et al. Development and validation of a patient-assessed gastroparesis symptom severity measure: the Gastroparesis Cardinal Symptom Index. Aliment Pharmacol Ther. 2003;18:141-50.

15. De la Loge $\mathrm{C}$ et al. Cross-cultural development and validation of a self-administered questionnaire to assess quality of life in upper gastrointestinal disorders. Qual Life Res. 2004;13:1751-62.

16. Bytzer $P$ et al. Prevalence of gastrointestinal symptoms associated with diabetes mellitus. Arch Intern Med. 2001;161:1989-96.

17. Hasler WL. Type 1 diabetes and gastroparesis: diagnosis and treatment. Curr Gastroenterol Rep. 2007;9:261-9.

18. Ordog T. Interstitial cells of Cajal in diabetic gastroenteropathy. Neurogastroenterol Motil. 2008;20:8-18.

19. Intagliata $\mathrm{N}$ et al. Gastroparesis in type 2 diabetes mellitus: prevalence, etiology, diagnosis, and treatment. Curr Gastroenterol Rep. 2007;9:270-9.

20. Watkins $\mathrm{CC}$ et al. Insulin restores neuronal nitric oxide synthase expression and function that lost in diabetic gastropathy. $\mathrm{J}$ Clin Invest. 2000;106(3):373-84.

21. Ordog $\mathrm{T}$ et al. Cellular pathogenesis of diabetic gastroenteropathy. Minerva Gastroenterol Dietol. 2009;55(3):315-43.

22. Kong MF et al. Gastric emptying in diabetes mellitus: relationship to blood-glucose control. Clin Geriatr Med. 1999;15:321-38.

23. Koch KL et al. Diabetic gastroparesis: comparison of clinical features in patients with Type 2 (T2DM) and Type 1 (T1DM) diabetes mellitus [abstract]. Am J Gastroenterol. 2009;104(Supp13):S56.

24. Izbéki $\mathrm{F}$ et al. The clinical picture, diagnosis and therapy of gastrointestinal autonomic neuropathy. In: Kempler P, Várkonyi T, editors. Neuropathies. A global clinical guide. Budapest: Zafír Press - Mona Lib Kft; 2012. p. 131-50.

25. MacGregor IL et al. The effect of acute hyperglycemia on gastric emptying in man. Gastroenterology. 1976;70:190-6.

26. Jebbink RJ et al. Hyperglycaemia induces abnormalities of gastric myoelectrical activity in patients with type I diabetes mellitus. Gastroenterology. 1994;107(5):1994-9.

27. Horváth VJ et al. Reduced insulin and IGF-I signaling, not hyperglycemia, underlies the diabetes-associated depletion of interstitial Cells of cajal in the murine stomach. Diabetes. 2005;54:1528-33.

28. Schvarcz E et al. Physiological hyperglycaemia slows gastric emptying in normal subjects and in patients with insulin-dependent diabetes mellitus. Gastroenterology. 1997;113(1):60-6.

29. Vittal H et al. Mechanisms of disease: the pathological basis of gastroparesis-a review of experimental and clinical studies. Nat Clin Pract Gastroenterol Hepatol. 2007;4(6):336-46.
30. Camilleri $\mathrm{M}$ et al. Relationship between impaired gastric emptying and abnormal gastrointestinal motility. Gastroenterology. 1986;91: 94-9.

31. Hirst GD et al. Electrical events underlying organized myogenic contractions of the guinea pig stomach. J Physiol. 2006;576:659-65.

32. Parkman HP et al. American gastroenterological association technical review on the diagnosis and treatment of gastroparesis. Gastroenterology. 2004;127:1592-622.

33. Nishikawa T et al. Normalizing mitochondrial superoxide production blocks three pathways of hyperglycaemic damage. Nature. 2000;404: 787-90.

34. Choi KM et al. Differences in protein expression between diabetic NOD mice with and without delayed gastric emptying. Gastroenterology. 2007;132:A-112.

35. Choi KM et al. Regulation of interstitial cells of Cajal in the mouse gastric body by neuronal nitric oxide. Neurogastroenterol Motil. 2007;19:585-95.

36. Harberson J et al. Gastric neuromuscular pathology in gastroparesis: analysis of full-thickness antral biopsies. Dig Dis Sci. 2010;10:359 70 .

37. Grover $\mathrm{M}$ et al. Clinical-histological associations in gastroparesis: results from the Gastroparesis Clinical Research Consortium. Neurogastroenterol Motil. 2012;24(6):531-40.

38. Selim MM et al. Gastric mucosal nerve density: a biomarker for diabetic autonom neuropathy? Neurology. 2010;75(11):973-81.

39. Gover M, NIDDK Gastroparesis Clinical Research Consortium, et al. Cellular changes in diabetic and idiopathic gastroparesis. Gastroenterology. 2011;140(5):1575-85.

40. Horváth VJ et al. Reduced stem cell factor links smooth myopathy and loss of interstitial cells of Cajal in murine diabetic gastroparesis. Gastroenterology. 2006;130(3):759-70.

41. Wu JJ et al. Development of the interstitial cell of Cajal: origin, kit dependence and neuronal and nonneuronal sources of kit ligand. J Neurosci Res. 2000;59(3):384-401.

42. Lorincz A et al. Progenitors of interstitial cells of Cajal in the postnatal murine stomach. Gastroenterology. 2008;134(4):1083-93.

43. Izbeki $\mathrm{F}$ et al. Loss of Kitlow progenitors, reduced stem cell factor and high oxidative stress underlie gastric dysfunction in progeric mice. J Physiol. 2010;588(16):3101-7.

44. Kempler $\mathrm{P}$ et al. On behalf of the Toronto Consensus Panel on Diabetic Neuropathy Gastrointestinal autonomic neuropathy, erectile-, bladder- and sudomotor dysfunction in patients with diabetes mellitus: clinical impact, assessment, diagnosis, and management. Diabetes Metab Res Rev. 2011;27:665-77.

45. Oh JH et al. Recent advances in the pathophysiology and treatment of gastroparesis. J Neurogastroenterol Motil. 2013;19(1):18-24.

46. Hasler WL. Gastroparesis: pathogenesis, diagnosis and management. Nat Rev Gastroenterol Hepatol. 2011;8(8):438-53.

47. Bolinder $\mathrm{J}$ et al. Autonomic neuropathy is associated with impaired pancreatic polypeptide and neuropeptide $\mathrm{Y}$ responses to insulininduced hypoglycaemia in Type I diabetic patients. Diabetologia. 2002;45(7):1043-4.

48. Kempler P, EURODIAB IDDM Complications Study Group, et al. Autonomic neuropathy is associated with increased cardiovascular risk factors: the EURODIAB IDDM Complications Study. Diabet Med. 2002;19(11):900-9.

49. Chang $\mathrm{J}$ et al. A 25-year longitudinal evaluation of gastric emptying in diabetes. Diabetes Care. 2012;35(12):2594-6.

50. Lam WF et al. Hyperglycemia reduces gastric secretory and plasma pancreatic polypeptide responses to modified sham feeding in humans. Digestion. 1993;54:48-53.

51. Yeap BB et al. Hyperglycemia affects cardiovascular autonomic nerve function in normal subjects. Diabetes Care. 1996;19(8):880-2.

52. Várkonyi $\mathrm{T}$ et al. Manifestations of diabetic polyneuropathy in the digestive tract and the central nervous system. Diabetol Hung. 2002;10 suppl 2:44-50. 
53. Pavy-Le Traon A et al. Cardiovascular autonomic neuropathy and other complications in type 1 diabetes. Clin Auton Res. 2010;20(3):153-60.

54. Lelic D et al. The brain networks encoding visceral sensation in patients with gastrointestinal symptoms due to diabetic neuropathy. Neurogastroenterol Motil. 2014;26(1):46-58.

55. Brock $\mathrm{C}$ et al. Peripheral and central nervous contribution to gastrointestinal symptoms in diabetic patients with autonomic neuropathy. Eur J Pain. 2012;17:820-31.

56. Várkonyi $\mathrm{T}$ et al. Severity of autonomic and sensory neuropathy and the impairment of visual- and auditory-evoked potentials in type 1 diabetes. Is there a relationship? Diabetes Care. 2006;29:2325-6.

57. Punkkinen J et al. Upper abdominal symptoms in patients with Type 1 diabetes: unrelated to impairment in gastric emptying caused by autonomic neuropathy. Diabet Med. 2008;25(5):570-7.

58. Søfteland E et al. Association between visceral, cardiac and sensorimotor polyneuropathies in diabetes mellitus. J Diabetes Complicat. 2013. doi:10.1016/j.jdiacomp.2013.10.009.

59. Chang $\mathbf{J}$ et al. Diabetic gastroparesis-backwards and forwards. J Gastroenterol Hepatol. 2011;26 Suppl 1:46-57.

60. Konturek JW et al. Effects of nitric oxide on antral motility and gastric emptying in humans. Eur J Gastroenterol Hepatol. 1995;7(2):97-102.

61. Maner WL et al. Diabetes induces sex-dependent changes in neuronal nitric oxide synthase dimerization and function in the rat gastric antrum. Am J Physiol Gastrointest Liver Physiol. 2007;292:725-33.

62. Micci MA et al. Neural stem cell transplantation in the stomach rescues gastric function in neuronal nitric oxide synthase-deficient mice. Gastroenterology. 2005;129(6):1817-24.

63. Pala L et al. Relationship between GLP-1 levels and dipeptidyl peptidase-4 activity in different glucose tolerance conditions. Diabet Med. 2010;27(6):691-5.

64. Ariga $\mathrm{H}$ et al. Ghrelin accelerates gastric emptying via early manifestation of antro-pyloric coordination in conscious rats. Regul Pept. 2008;146(1-3):112-6.

65. Falkén $Y$ et al. Actions of prolonged ghrelin infusion on gastrointestinal transit and glucose homeostasis in humans. Neurogastroenterol Motil. 2010;22(6):192-200

66. Kojima $\mathrm{M}$ et al. Ghrelin: structure and function. Physiol Rev. 2005;85(2):495-522.

67. Gaddipati KV et al. Abnormal ghrelin and pancreatic polypeptides responses in gastroparesis. Dig Dis Sci. 2006;51(8):1339-46.

68. Kan $\mathrm{M}$ et al. Glucagon-like peptide 1 , insulin, sensory neurons, and diabetic neuropathy. J Neuropathol Exp Neurol. 2012;71(6):494-510.

69. Sam AH et al. Selective ablation of peptide YY cells in adult mice reveals their role in beta cell survival. Gastroenterology. 2012;143(2):459-69.

70. Rühl A. Glial cells in the gut. Neurogastroenterol Motil. 2005;17: 777-9.

71. Nezami BG. Enteric nervous system in the small intestine: pathophysiology and clinical implications. Curr Gastroenterol Rep. 2010;12:358-5.

72. Aubé AC et al. Changes in enteric neurone phenotype and intestinal functions in a transgenic mouse model of enteric glia disruption. Gut. 2006;55(5):630-7.

73. Abdo $\mathrm{H}$ et al. Enteric glial cells protect neurons from oxidative stress in part via reduced glutathione. FASEB J. 2010;24(4):1082-94.

74. Chandrasekharan B et al. Diabetes and the enteric nervous system. Neurogastroenterol Motil. 2007;19(12):951-60.

75. Abell TL et al. Consensus recommendations for gastric emptying scintigraphy: a joint report of the American Neurogastroenterology and Motility Society and the Society of Nuclear Medicine. J Nucl Med Technol. 2008;36:44-54.

76. Gilja OH. Ultrasound of the stomach - the EUROSON lecture 2006. Ultraschall Med. 2007;28:32-9.
77. Marzio L et al. Evaluation of the use of ultrasonography in the study of liquid gastric emptying. Am J Gastroenterol. 1989;84:496-500.

78. Stevens JE et al. Measurement of gastric emptying of a high-nutrient liquid by $3 \mathrm{D}$ ultrasonography in diabetic gastroparesis. Neurogastroenterol Motil. 2011;23:220-5.

79. Olausson EA et al. Small particle size of a solid meal increases gastric emptying and late postprandial glycaemic response in diabetic subjects with gastroparesis. Diabetes Res Clin Pract. 2008;80:231-7.

80. Perkel MS et al. Metoclopramide therapy in patients with delayed gastric emptying: a randomized, double-blind study. Dig Dis Sci. 1979;24:662-6.

81. Van Thiel DH. Effect of metoclopramide on gastric liquid emptying in patients with diabetic gastroparesis. Dig Dis Sci. 1985;30:10-5.

82. Ricci DA et al. Effect of metoclopramide in diabetic gastroparesis. J Clin Gastroenterol. 1985;7:25-32.

83. Henry $\mathrm{P}$ et al. Clinical response and side effects of metoclopramide associations with clinical, demographic, and pharmacogenetic parameters. J Clin Gastroenterol. 2012;46:494-503.

84. Strauss SM et al. Non-cardiac QTc-prolonging drugs and the risk of sudden cardiac death. Eur Heart J. 2005;26:2007-12.

85. Lin $\mathrm{HC}$ et al. Erythromycin accelerates solid emptying at the expense of gastric sieving. Dig Dis Sci. 1994;39:124-8.

86. Moshiree B et al. Comparison of the effect of azithromycin versus erythromycin on antroduodenal pressure profiles of patients with chronic functional gastrointestinal pain and gastroparesis. Dig Dis Sci. 2010;55(3):675-83.

87. Ray WA et al. Oral erythromycin and the risk of sudden death from cardiac causes. N Engl J Med. 2004;351:1089-96.

88. Várkonyi T et al. Diabetic neuropathy: new strategies for treatment. Diabetes Obes Metab. 2008;10:99-108.

89. Ziegler D et al. Effects of treatment with the antioxidant alpha-lipoic acid on cardiac autonomic neuropathy in NIDDM patients. A 4month randomized controlled multicenter trial (DEKAN Study). Deutsche Kardiale Autonome Neuropathie. Diabetes Care. 1997;20(3):369-73.

90. Várkonyi Tet al. Current options and perspectives in the treatment of diabetic neuropathy. Curr Pharm Des. 2013;19(27):4981-5007.

91. Wo JM et al. Randomised clinical trial: ghrelin agonist TZP101 relieves gastroparesis associated with severe nausea and vomiting-randomised clinical study subset data. Aliment Pharmacol Ther. 2011;33:679-88.

92. Camilleri $\mathrm{M}$ et al. A ghrelin agonist fails to show benefit in patients with diabetic gastroparesis: let's not throw the baby out with the bath water. Neurogastroenterol Motil. 2013;25(11):859-63.

93. Chong $\mathrm{K}$ et al. A case of severe, refractory diabetic gastroparesis managed by prolonged use of aprepitant. Nat Rev Endocrinol. 2009;5:285-8.

94. Abell $\mathrm{T}$ et al. Gastric electrical stimulation for medically refractory gastroparesis. Gastroenterology. 2003;125(2):421-8.

95. Kim KH et al. Acupuncture for symptomatic relief of gastroparesis in a diabetic haemodialysis patient. Acupunct Med. 2010;28:101-3.

96. Lin $\mathrm{Z}$ et al. Association between changes in symptoms and gastric emptying in gastroparetic patients treated with gastric electrical stimulation. Neurogastroenterol Motil. 2008;20:46470.

97. Abell TL et al. Gastric electrical stimulation in intractable symptomatic gastroparesis. Digestion. 2002;66:204-12.

98. McCallum RW et al. Gastric pacing improves emptying and symptoms in patients with gastroparesis. Gastroenterology. 1998;114:45661.

99. Fontana RJ et al. Jejunostomy tube placement in refractory diabetic gastroparesis: a retrospective review. Am J Gastroenterol. 1996;91: 2174-8. 